DOI: $10.29303 /$ jrpb.v8i2.194

ISSN 2301-8119, e-ISSN 2443-1354

Tersedia online di http://jrpb.unram.ac.id

\title{
ASSESSMENT OF WORK POSTURES ON NON-MECHANICAL RICE HARVESTING (CASE STUDIES IN BANTUL AND SLEMAN DISTRICTS, DIY PROVINCE)
}

\section{Guntarti Tatik Mulyati, ${ }^{1,2}$, Muhammad Maksum¹, Bambang Purwantana ${ }^{2}$, Makhmudun Ainuri ${ }^{1}$}

\author{
${ }^{1}$ Department of Agroindustry, Faculty of Agricultural Technology, Universitas Gadjah Mada, \\ Jl. Flora No. 1, Bulaksumur, Yogyakarta 55281, Indonesia \\ ${ }^{2}$ Department of Agricultural and Biosystem Engineering, Faculty of Agricultural Technology, \\ Universitas Gadjah Mada, Jl. Flora No. 1, Bulaksumur, Yogyakarta 55281, Indonesia
}

\section{Email ${ }^{*}$ : guntarti.ftp@ugm.ac.id}

Accepted: Juli 2020

Approved: September 2020

\begin{abstract}
Rice harvesting is a high ergonomic risk due to the working position, an awkward posture, and the repetition activity. Rice harvesting causes body pain in the part of low back, hand, and wrist. This study aims to (1) identify the characteristics of non-mechanical rice harvesting; (2) determine the working posture of rice harvesters using the Ovako Working Assessment System (OWAS) method, Quick Exposure Checklist (QEC), Rapid Entire Body Assessment (REBA), Postural Ergonomics Risk Assessment (PERA); and (3) determine the best method to assess harvesters work posture. An observation was conducted to nine of healthy workers in Bantul and Sleman districts, Daerah Istimewa Yogyakarta (DIY) province. The questionnaire was set to collect respondent demographics data. Data for harvester body posture (neck, trunk, leg, wrist, lifting load, shoulder) repetition, duration and force were collected by observation in the field. A sickle was used to cut rice straw, while a manual gepyok and mobile hand thresher was used to threshing rice panicles. Four methods were applied to assess the work posture, i.e., OWAS, QEC, REBA, PERA methods. Based on observation, five workstations were identified: (1) cutting rice straw, (2) transporting rice straw, (3) threshing of panicles, (4) sorting, and (5) packaging and transporting. REBA and PERA showed a similar trend of the ergonomic risk, high to low risk took place in workstation transporting rice straw, packaging and transporting, cutting, and threshing. The assessment of work posture that is most suitable for non-mechanical harvesting methods was the REBA method with an accuracy of $92.9 \%$.
\end{abstract}

Keywords: ergonomic, non-mechanical, posture, rice-harvesting

\section{INTRODUCTION}

\section{Background}

Rice harvesting activities sometimes use heavy equipment, awkward postures, and lots of repetitive movements. These factors were related to Work-Related
Musculoskeletal Disorders (WMSDs) or MSDs. The best way to reduce WMSDs is to redesign equipment and process improvements using the principle of ergonomics. Relatively small changes in equipment design can make a big difference in performance (Baron et al., 2001). The use 
of new gepyok design in conventional rice harvesting can improve the harvester's working posture, reducing work-related pain, and harvesting workload (Sa'diyah et al., 2019). New gepyok design is a triangular prism-shaped object, with one side made of rows of small metal which is used as a foundation for slamming rice stalks so that the grain falls.

To secure worker safety from ergonomic risk, specifically on posture, there are some methods that could be employed to evaluate and assess it. There are some methods of worker posture assessment to determine the risk level of workers MSDs, e.g. Quick Exposure Checklist (QEC), Rapid Upper Limb Assessment (RULA), Rapid Entire Body Assessment (REBA), the Occupational Repetitive Action (OCRA) and others (Stanton et al., 2005). These methods identify the risk of worker posture by evaluating and assessing the body part movement trunk, hand, leg, and other factors. Every method has merits and demerits.

Many workers stand for long periods of time without the opportunity to walk or sit down. Working in a standing posture on a daily basis can cause pain in the soles of the feet, swelling in the legs, enlarged blood vessels, muscle fatigue, low back pain, stiffness in the neck and shoulders, and other health problems (Waters \& Dick, 2015). In the case of a pregnant worker, these effects can cause preterm birth and spontaneous abortion (Vaidya et al., 2014).

An activity such as repetitive work and awkward posture are the main factors of ergonomic risk (Chander \& Cavatorta, 2017). Correlation of a worker ergonomic risk and MSDs has not known certainly, because $83 \%$ of worker does not realize ergonomic action (Boschman et al., 2015).

Karhu et al. (1977) published the first method of harvester posture assessment, Ovako Working Assessment System (OWAS). It was a simple method but does not consider the interaction of worker's body part; such that the accuracy is less (Hellig et al., 2018). The advantages of this method are evaluating leg posture when sitting and walking. QEC was designed to evaluate the work experience of the observer, practitioner, and workers ( $\mathrm{Li} \&$ Buckle, 1998). RULA and REBA evaluate worker posture more detail by including movement of the neck, shoulder, arm, and hand, clutch as well as load lifting frequency. REBA developed by Hignett \& McAtamney (2000) for industry application. It provides rapid and simple methods to measure several worker postures which risky to WMSDs.

REBA defines a neutral posture by evaluating the angle of body joints, and this method classifies the worker's leg position. These points do not include in the RULA method (McAtamney \& Corlett, 1993). RULA has excellent performance to evaluate the ergonomic risk in case of working while sitting (Al Madani \& Dababneh, 2016). Chander \& Cavatorta (2017) introduces the PERA method that can be used to evaluate the ergonomic risk of short cyclic work. It enables us to determine the main factor of cyclic work by focusing on the analysis of worker posture when working (Ahmadi \& Salmanzadeh, 2018). PERA overcomes obstacle the assessment method of ergonomic risk for cyclic work.

Rice harvesting causes body pain in the part of the low back, hand, and wrist (Swangnetr et al., 2014). Physiological fatigue due to working while standing for long periods can be assessed subjectively with a survey questionnaire using the Borg scale or the Body Part Symptom Survey (van Dieën, 2010).

Period of work time has not considered in OWAS and REBA. It makes them cannot be applied to evaluate a cyclic work (Chander \& Cavatorta, 2017). Rice harvesting covers all activity in the field, starting from cutting rice straw to releasing the grains from panicles (Sulistiaji, 2007). It includes manual working such as cutting rice straw by using a sickle, transporting rice straw to thresher machine, threshing the grains, sorting the grains, weighing, packaging, and transporting sacked rice. These activities can be done by standing, 
bending, walking while bringing a mass, standing for the operating machine, and squatting down. It means that rice harvesting activities are an awkward work posture, e.g. squatting down $>60^{\circ}$, walking while bringing a huge mass. This study was focused on evaluating using OWAS, QEC, REBA, and PERA methods for work posture assessment of rice harvesting by using the non-mechanical method. Work posture is a significant cause of muscle problems MSDs (Iridiastadi \& Yasierli, 2014).

\section{Objective}

The study aimed to learn OWAS, QEC, REBA, and PERA methods for work posture assessment of rice harvesting and determine the best method for assessing the harvester's work posture. The results of the assessment of work posture and assessment of the suitability of the physical size of the tool with anthropometry of workers will be used to redesign work equipment to reduce MSDs risk.

\section{METHODOLOGY}

\section{The characteristics of respondents}

Respondents were nine healthy harvesters in Bantul and Sleman districts, Daerah Istimewa Yogyakarta province. The questionnaires were used to collect respondent demographic data. Work posture data in the form of video recordings and photographs were collected by observing harvesting in the field. Data were collected on $14-16^{\text {th }}$ November 2019 . The respondents consisted of $44 \%$ female harvesters and $56 \%$ male harvesters. The average age of respondents was 53 years, with 21 years of experience as harvesters. Sixty percent of respondents were of interest in elementary school.

Non-mechanical method of rice harvesting was defined as (1) manual cutting and threshing, (2) manual cutting and semimechanical threshing. The harvester worked full a week during harvesting season. Rice harvesting starts at $05.30 \mathrm{AM}$ by cutting rice straw. This activity is fast and continual to collect as much as possible the materials before the sun is getting hotter. All member of the group takes a break at $08.00 \mathrm{AM}$ for breakfast. Some harvester groups set up tents to reduce the impact of the sun's heat.

\section{The design and setting of the study}

Four methods, e.g. OWAS (Karhu et al., 1977), QEC (Li \& Buckle, 1998; (Godsiff et al., 2008)), REBA and PERA (Chander \& Cavatorta, 2017) were applied to evaluate work posture.

OWAS method does not evaluate posture of neck, trunk, and hand in detail but it considers posture of leg and position of working (sitting on the chair, moderate squatting down, and walking). The evaluation of work posture in QEC method is conducting by observer and worker. It is similar with OWAS, in which the evaluation on body parts have less attention but the repetitive work has been more explored. REBA method is intent in evaluating upper part of body. Furthermore, it includes evaluation on the stand up straightness of leg position, coupling, static muscle work (holding something more than 1 minute), and repetitive working while unstable standing. PERA method more concerns in evaluating work posture when repetitive working in a short cycle.

The study started by documenting the rice harvesting activity. Data was input to OWAS, QEC, REBA, and PERA, and classified into Method Score. Each method has a different final score that listed in the $\mathrm{S}$ column of each method. OWAS score: 1-4, QEC score: 40-70\%, REBA final score: 112 and PERA score 1-7. The score of each method is classified into the Action Level in the AL column of each method. OWAS action level: 1-4, QEC action level: 1-4, REBA action level: 0-4, and PERA action level: 1-3. This action level illustrates the level of risk faced by the activity assessed by its work posture (level of risk column). It can be used to assign the recommendation to minimize MSDs of the worker. The method score, action level, risk and recommendation of each method was classified in Table 1. 
Table 1. The Method Score, Action Level Score, Level of Risk and Recommendation of OWAS, QEC, REBA and PERA Methods

\begin{tabular}{|c|c|c|c|c|c|c|c|c|c|}
\hline \multicolumn{8}{|c|}{ Methods } & \multirow{3}{*}{ Level of risk } & \multirow{3}{*}{ Recommendation } \\
\hline \multicolumn{2}{|c|}{ OWAS* } & \multicolumn{2}{|c|}{$\mathrm{QEC}^{* *}$} & \multicolumn{2}{|c|}{ REBA** } & \multicolumn{2}{|c|}{ PERA*** } & & \\
\hline $\mathrm{S}$ & $\mathrm{AL}$ & $\mathrm{S}$ & $\mathrm{AL}$ & $\mathrm{S}$ & $\mathrm{AL}$ & $\mathrm{S}$ & $\mathrm{AL}$ & & \\
\hline 1 & 1 & $\leq 40$ & 1 & 1 & 0 & $\mathrm{~A}<4$ & 1 & Negligible risk & Acceptable \\
\hline 2 & 2 & $41-50$ & 2 & $2-3$ & 1 & & & Low risk & $\begin{array}{l}\text { Further investigation, } \\
\text { manipulations are required }\end{array}$ \\
\hline 3 & 3 & $51-70$ & 3 & $4-7$ & 2 & $4 \leq \mathrm{A}<7$ & 2 & $\begin{array}{c}\text { Medium/ } \\
\text { possible risk }\end{array}$ & $\begin{array}{l}\text { Further investigation and } \\
\text { manipulations are urgent }\end{array}$ \\
\hline \multirow[t]{2}{*}{4} & 4 & $>70$ & 4 & $8-10$ & 3 & $A \geq 7$ & 3 & High risk & $\begin{array}{l}\text { Investigation and } \\
\text { straightway manipulation }\end{array}$ \\
\hline & & & & $11+$ & 4 & & & Very High risk & $\begin{array}{l}\text { Investigation and } \\
\text { straightway manipulation }\end{array}$ \\
\hline
\end{tabular}

Note: $\mathrm{S}=$ method score; $\mathrm{AL}=$ method action level; * = Hellig et al., (2018); ** = Stanton et al., (2005); *** = Chander \& Cavatorta, 2017

\section{RESULTS AND DISCUSSION}

\section{Manual and Semi-Mechanical Rice Harvesting Method}

Non-mechanical harvesting activities start from cutting rice straw manually using sickle, followed by threshing activities using gepyok or hand thresher. Gepyok and hand thresher was put in the middle part of the land. Rice straws collected around the thresher. Simultaneously, the harvester did threshing the grain from panicles. The threshing activity was followed by the sorting activity. After these two activities completed, the grain was packed and transporting. Based on these steps, this study identified 5 work-stations in manual and semi-mechanical rice harvesting and 19 work elements (Table 2).

Table 2. Work-stations and Work-elements of Non-Mechanical Rice Harvesting Method

\begin{tabular}{|c|c|c|}
\hline No & Work-stations & Work- elements \\
\hline 1 & Cutting & $\begin{array}{l}\text { (a) cutting, (b) placing, } \\
\text { (c) moving \& relaxing }\end{array}$ \\
\hline 2 & Transporting & $\begin{array}{l}\text { (a) taking the collected rice } \\
\text { straw, (b) amassing \&lifting, } \\
\text { (c) transporting the amassed rice } \\
\text { straw to the thresher }\end{array}$ \\
\hline 3 & Threshing & $\begin{array}{l}\text { (a) placing thresher, (b) taking } \\
\text { rice straw, (c) carrying, (d) } \\
\text { threshing the grain, (e) } \\
\text { disposing the straw }\end{array}$ \\
\hline 4 & Sorting & $\begin{array}{l}\text { (a) sorting the straw, (b) sorting } \\
\text { the rice, (c) winnowing, } \\
\text { (d) collecting the selected rice }\end{array}$ \\
\hline 5 & $\begin{array}{l}\text { Packaging } \\
\text { and } \\
\text { tranporting }\end{array}$ & $\begin{array}{l}\text { (a) preparing the sacks, } \\
\text { (b) measuring \& packaging, } \\
\text { (c) lifting the sacked rice, } \\
\text { (d) transporting the sacked rice }\end{array}$ \\
\hline
\end{tabular}

Activities at each workstation were recorded in Figure 1-3.

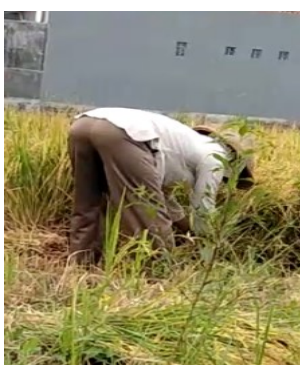

(a)

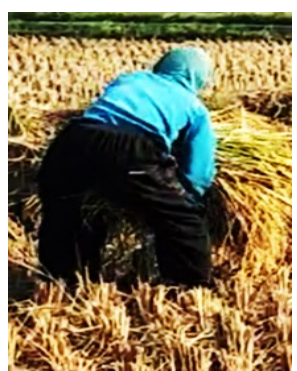

(b)
Figure 1. (a) Cutting, (b) Transporting

Figure 1 shows cutting activity and transporting rice straw to threshing workstation. Activities in cutting and transportation are mostly done by bending. Figure 2 was a threshing activity, (a) manual gepyok, (b) hand threshing.

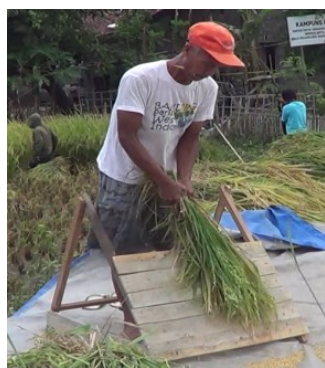

(a)

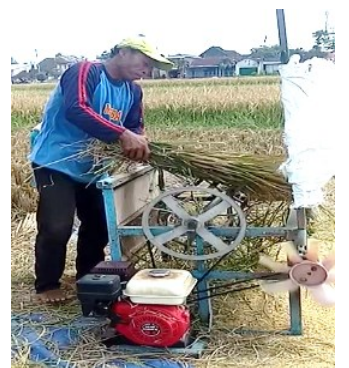

(b)
Figure 2. Threshing Activity: (a) Manual Gepyok, (b) Hand Thresher

Sorting activity is the activity of separating unhulled rice from the following pieces of rice stalks, is done by taking the material at the bottom of the thresher by squatting. Grain is packed in $50 \mathrm{~kg}$ sacks. 
Sacks were delivered to the owner's house (Figure 3).

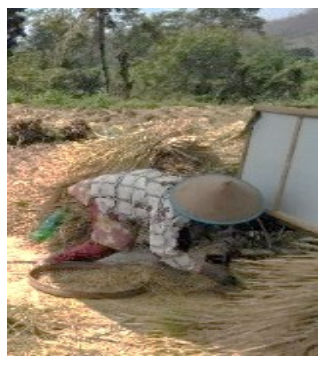

(a)

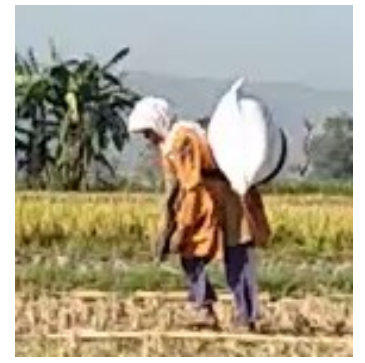

(b)
Figure 3. (a) Sorting, (b) Packaging and transporting

\section{Work posture assessment}

The score of work posture assessment were done using 4 methods presented in Table 3 . The workstation 3 describes manual gepyok (3a) and semi-mechanical Hand Thresher (3b) activities. Score was derived from a posture assessment using the appropriate method, respectively. From table 3 PERA method, some activities have an extreme high score (score 27) such as in the rice straw cutting and in the manual threshing way of gepyok. At work-station 1, $70 \%$ of the time was spent cutting rice stalks with a bow, resulting in a very high risk assessment.

In manually, worker must exert a very large force that is not assessed in other methods. Cutting rice activity, while bending almost $90^{\circ}$, leads to the judgment of the neck and the trunk in the REBA method was highly rated (11). The REBA assessment was very high in the amassing \& lifting (2b) because the activity by bending and carrying the load. Similarly, this phenomenon also occurs in packaging and transportation activities. The OWAS and QEC assessments did not give the same results because the important considerations in these methods differed from the REBA and PERA. Table 3 shows the action level for each method and each work element.

Table 3. Score Posture and Action Level of Each Work Element

\begin{tabular}{|c|c|c|c|c|c|c|c|c|c|}
\hline \multirow{3}{*}{ No. } & \multirow{3}{*}{ Work element } & \multicolumn{8}{|c|}{ Methods } \\
\hline & & \multicolumn{2}{|c|}{ OWAS } & \multicolumn{2}{|c|}{ QEC } & \multicolumn{2}{|c|}{ REBA } & \multicolumn{2}{|c|}{ PERA } \\
\hline & & $\mathrm{S}$ & $\mathrm{AL}$ & $\mathrm{S}$ & $\mathrm{AL}$ & $\mathrm{S}$ & $\mathrm{AL}$ & $\mathrm{S}$ & $\mathrm{AL}$ \\
\hline \multirow[t]{3}{*}{1} & (a) cutting rice & 2 & 2 & 2 & 2 & 11 & 4 & 27 & 3 \\
\hline & (b) placing & 2 & 2 & 1 & 1 & 7 & 2 & 4 & 2 \\
\hline & (c) transporting & 1 & 1 & 1 & 1 & 1 & 0 & 2 & 1 \\
\hline \multirow[t]{3}{*}{2} & (a) taking the collected rice & 2 & 2 & 1 & 1 & 7 & 2 & 18 & 3 \\
\hline & (b) amassing \&lifting & 1 & 1 & 2 & 2 & 11 & 4 & 12 & 3 \\
\hline & (c) transporting the amassed rice & 1 & 1 & 1 & 1 & 4 & 2 & 6 & 2 \\
\hline \multirow[t]{5}{*}{$3 a$} & (a) placing thresher & 3 & 3 & 2 & 2 & 7 & 2 & $*$ & $*$ \\
\hline & (b) taking rice straw & 1 & 1 & 1 & 1 & 6 & 2 & 4 & 2 \\
\hline & (c) carrying & 1 & 1 & 1 & 1 & 4 & 2 & 4 & 2 \\
\hline & (d) threshing & 1 & 1 & 1 & 1 & 5 & 2 & 27 & 3 \\
\hline & (e) disposing the straw & 1 & 1 & 1 & 1 & 2 & 1 & 1 & 1 \\
\hline \multirow[t]{5}{*}{$3 b$} & (a) placing thresher & 3 & 3 & 2 & 2 & 7 & 2 & $*$ & $*$ \\
\hline & (b) taking rice straw & 1 & 1 & 1 & 1 & 6 & 2 & 4 & 2 \\
\hline & (c) carrying & 1 & 1 & 1 & 1 & 4 & 2 & 4 & 2 \\
\hline & (d) threshing the grain & 1 & 1 & 1 & 1 & 5 & 2 & 18 & 3 \\
\hline & (e) disposing the straw & 1 & 1 & 1 & 1 & 2 & 1 & 1 & 1 \\
\hline \multirow[t]{4}{*}{4} & (a) sorting the straw & 4 & 4 & 2 & 2 & 10 & 3 & $* *$ & ** \\
\hline & (b) sorting the rice & 4 & 4 & 2 & 2 & 10 & 3 & & \\
\hline & (c) winnowing & 2 & 2 & 1 & 1 & 7 & 2 & & \\
\hline & (d) collecting the selected rice & 2 & 2 & 1 & 1 & 8 & 3 & & \\
\hline \multirow[t]{4}{*}{5} & (a) preparing & 1 & 1 & 1 & 1 & 1 & 0 & 1 & 1 \\
\hline & (b) measuring \& packaging & 4 & 4 & 1 & 1 & 7 & 2 & 18 & 3 \\
\hline & (c) lifting & 3 & 3 & 3 & 3 & 11 & 4 & 6 & 2 \\
\hline & (d) transporting & 3 & 3 & 2 & 2 & 11 & 4 & 18 & 3 \\
\hline
\end{tabular}

Note: $\mathrm{S}=$ method score, $\mathrm{AL}=$ method action kevel, ${ }^{*}=$ non cyclic work because only once in a day, $* *=$ duration is long time 
Table 4. Classification of Risk Score Into 3 Classes

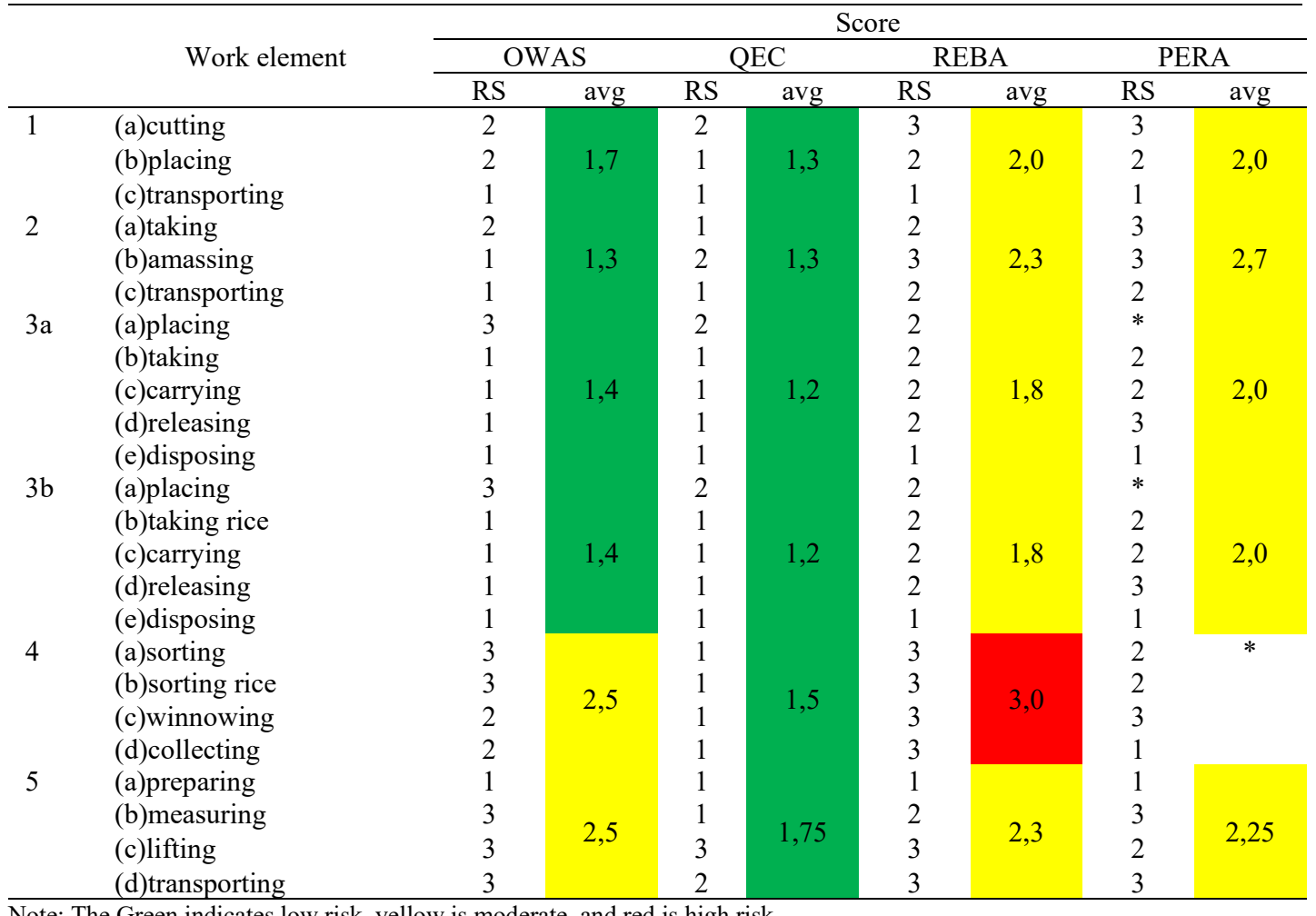

Note: The Green indicates low risk, yellow is moderate, and red is high risk

From Table 3, this action level is obtained by following the work posture assessment stages in each method as shown in Table 1 . The $1^{\text {st }}$ work element was the cutting rice straw with OWAS score 2 action level 2, QEC score 2 action level 2, REBA score 11 action level 4, PERA score 27 action level 3. The score of the work elements in one workstation was averaged. Action level values for OWAS method are 4, QEC 3, REBA 5 and PERA 3. To compare four methods, a new classification for action level was made. For comparing the method, the average score (x) was classified into 3 classes. Low risk (score: 1 ) if $\mathrm{x}<2$, the color is green, medium risk (score: 2 ) if $2 \leq x<3$, the color is yellow, and high risk (score: 3 ) if $x \geq 3$, the color is red. The result can be seen in Table 4 . Referring to Table 1, recommendations for the green ones are good work postures and risks are acceptable. The yellow ones means that need further investigation and may need some improvements in the future. The red ones mean need investigation immediately and straightway improvement.

Based on Table 4, the OWAS method gives a low rate at workstations 1,2, and 3, medium at workstation 4 and 5. The QEC method evaluates all workstation in low risk. The REBA and PERA methods provide the same risk assessment results in terms of the medium risk workstation sequences in terms of MSDs. If sorted from those most at risk to those not at risk, the sequence of workstations was $4,2,5,1$, and 3 .

The assessment was carried out by identifying the percentage of body parts and activities of rice harvesting that have been assessed by the REBA and PERA methods (Table 5). From Table 5, it can be seen that the activity of harvesting rice in paddy fields involves the neck and trunk posture, which is closely related to the angle of movement, where the neck posture is assessed in the QEC, REBA and PERA methods, while the trunk is assessed by all methods. 
Table 5. Body Part and Activity that Assess by OWAS, QEC, REBA and PERA

\begin{tabular}{llcccc}
\hline \multicolumn{1}{c}{ Part of the body / activity } & OWAS & QEC & REBA & PERA \\
\hline 1 & Neck & - & $*$ & $*$ & $*$ \\
2 & Trunk & $*$ & $*$ & $*$ & $*$ \\
3 & Angle of movement & - & - & $*$ & $*$ \\
4 & Leg (standing/ kneeling/walking) & $*$ & $*$ & $*$ & $*$ \\
5 & Load & $*$ & $*$ & $*$ & - \\
6 & Upper arm/shoulder & $*$ & $*$ & $*$ & $*$ \\
7 & Static muscle/monotonous movement & - & $*$ & $*$ & - \\
8 & Dynamic movement & $*$ & $*$ & $*$ & $*$ \\
9 & Repetitive task & - & $*$ & $*$ & $*$ \\
10 & Coupling & - & - & $*$ & - \\
11 & Force & - & - & - & $*$ \\
12 & Duration of task & - & $*$ & $*$ & $*$ \\
13 & twisted & $*$ & - & $*$ & - \\
14 & bending & $*$ & - & $*$ & - \\
\multicolumn{2}{r}{ Percent accuracy $(\%)$} & 7 & 9 & 13 & 9 \\
\hline
\end{tabular}

The angle of movement of the neck and trunk is only assessed in the REBA and PERA methods, not in the OWAS and QEC methods, etc. In total, there are 12 characteristics of rice harvesting activities that are closely related to work posture assessment. Based on Table 5, posture assessment using the REBA method is an appropriate method for rice harvesting activities, considering that $92.9 \%$ of posture characteristics can be assessed by REBA. The REBA method can be used to assess the posture of all parts of the body and is very good for assessing work that is static and dynamic (Hashim et al., 2012). The OWAS method assesses 7 harvest characteristics out of 14 valued or $50.0 \%$, QEC $64.3 \%$, REBA 92.9\% and PERA $64.3 \%$.

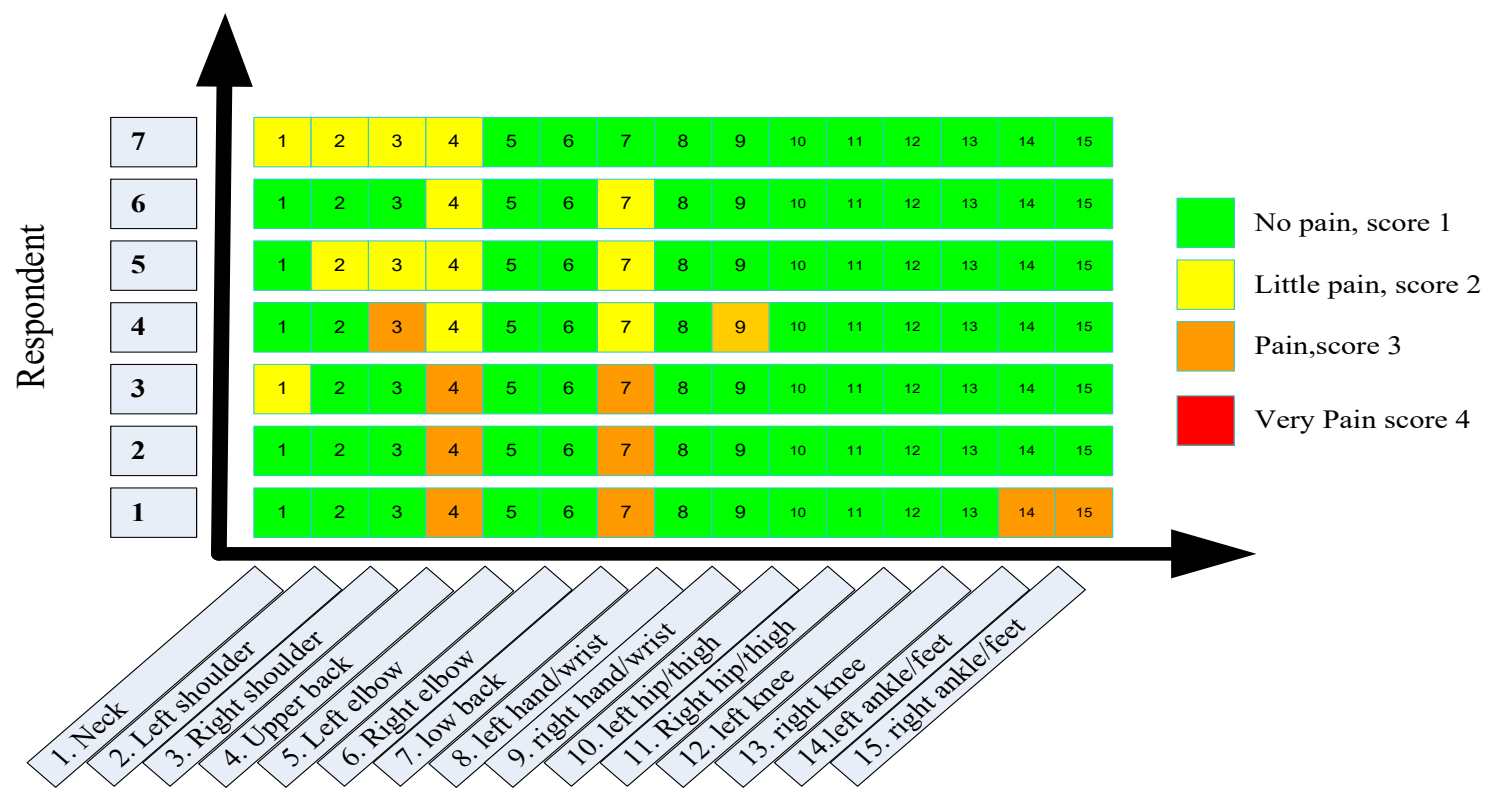

Body part

Figure 4. Pain Mapping due to Work in Rice Harvesting by using Manual Gepyok Method (Mulyati et al., 2019)

To develop corrective measures such as in the case of work posture assessment, it is necessary to assess workload by analyzing the risk of MSDs (Hellig et al., 2018). 
Supporting data are required like Standard Nordic Questionnaire that could describe an injury or pain when rice harvesting was finished. Mulyati et al., (2019) realized that manual gepyok and semi mechanical rice harvesting by using hand thresher issued score of pain assessment as seen in Figure 4 and 5. The Figure illustrates pain assessment when working that evaluated objectively by worker using Standard Nordic Questionnaire. The color of green means there is no pain in the body. Yellow, orange, and red colors indicate the level of pain when working is finished. Yellow means little pain, orange pain, and red very pain. $Y$ axis should be Respondent and $\mathrm{X}$ axis should be "body part". The colored boxes inform pain level of workers after full day activity.

On Figure 4, respondent number 1 have 2 colored boxes, green, and orange. The orange box with written number 4 and 7 means the pains were in upper and lower back, while number 14 and 15 means the pain were at the left and right ankle/feet. The green boxes state no pain.

Manual workers using gepyok had feel pain in the upper and lower back because they must exert energy during threshing the rice. As a result of the use of considerable energy, the workload represented by the heart rate of the worker ( \pm 115 beats/minute) is at moderate levels (Mulyati et al., 2020). This workload is at the same level of a hand tractor operator who has a heart rate of 100125 beats/minute (Sulnawati et al., 2016). If the rice harvester feels pain due to the use of excess muscle, the hand tractor machine operator's pain is caused by the vibration and noise of the engine.

Figure 5 shows the results of workrelated pain mapping for threshing using a hand thresher. On the Figure 5, respondent number 2 feel pain in lower back. The left hand less pain than right hand. Since the harvesting workers must hold the rice straw tightly from work element number 2 to 5 . This work posture is a static muscle. Charles et al., (2017) underlined that static muscle in long leads the blood does not flow smoothly, the energy decrease, lactic acid in the muscle is accumulated then raise fatigue, pain increases while hand power declines.

Working while standing in a long time induces fatigue that happen after 2 hours standing all the time, where it raises a static contraction in and back too.

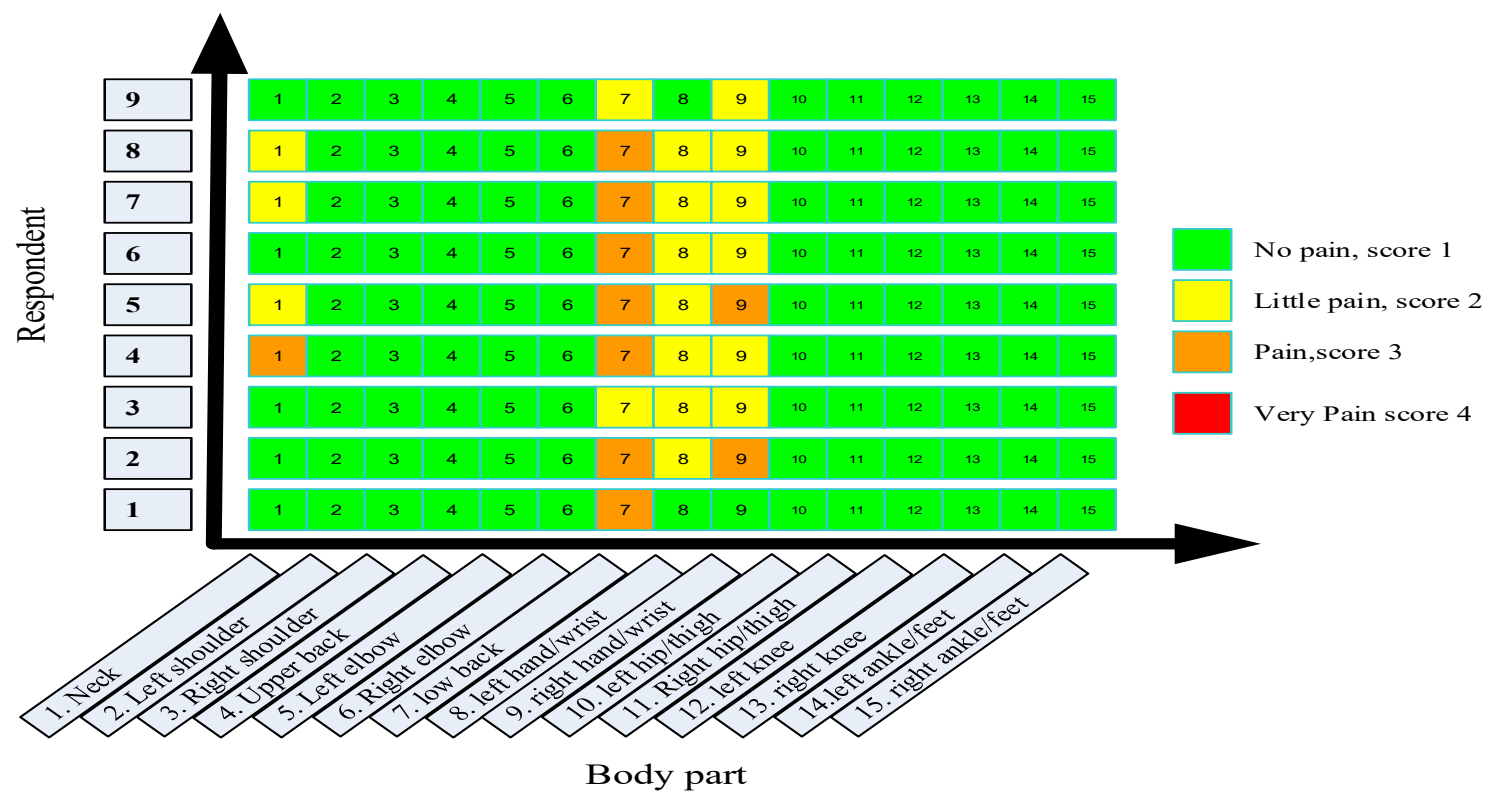

Figure 5. Pain Mapping due to Work in Rice Harvesting by using Semi-Mechanical Method (Mulyati et al., 2019) 
When experiencing static contraction, the calf muscle malfunctioning then uncomfortable and tired (Halim et al., 2012). High scored activity by REBA were stoop $>60^{\circ}$ in workstation $1,2,4,5$, lifting a mass in workstation 2 and 5 which caused bad impact in lower back and hands. The manual harvest method gepyok and semimechanical hand thresher has the same REBA posture score but has a different score of pain due to Standard Nordic Questionnaire.

Harvesting rice by gepyok resulted pain in the upper and lower back. In the threshing process harvester should raise the hand holding the rice straw followed by bending the tip of the rice straw into the gepyok tool. The pain in the upper and lower back is caused by the activity position of higher than the shoulder and quickly bending over $60^{\circ}$ while swinging hands firmly.

In semi mechanical threshing by hand thresher, the harvester holds the rice straw and directs the tip to the thresher cylinder until the grain is released. Painful limbs are reported at the lower back and hand. Harvester must hold rice straw continuously. Hold rice straw in a static muscle cause a fatigue.

\section{CONCLUSION}

Activities of non-mechanical rice harvesting were involving static and dynamic muscles, repetitive, most were cyclic with short cycle time, and using a tremendous force when threshing manually. Harvesters work on standing posture for more than $50 \%$ of working time, stoop more than $60 \%$, squatting or kneeling, and carrying heavy loads. Posture assessments using OWAS and QEC methods showed that the activity could be classified as a lowmoderate risk level. While assessment using REBA and PERA methods results a moderate-high risk of harvesting and showed a similar trend of the ergonomic risk. Work posture assessment method that had most suitable for non-mechanical rice harvesting was the REBA method have accuracy of $92.9 \%$.

\section{ACKNOWLEDGEMENT}

Thank you to the Doctoral Program in Agricultural Engineering FTP UGM. This research and publication is part of Dissertation entitled "Ergonomic Intervention Based on Technology Level Harvesting of Rice (Oryza Sativa) To Reduce Risk of Musculoskeletal Disorders Harvesters"

\section{REFERENCES}

Ahmadi, M., \& Salmanzadeh, H. (2018). Application of PERA method to analyze and redesign the cyclic tasks in an automotive industry. Iran Occupational Health, 15(5), 38-47. http://shafaorthoj.com/journalsys/ioh/ article-1-2369-en.html.

Al Madani, D., \& Dababneh, A. (2016). Rapid entire body assessment: A literature review. In American Journal of Engineering and Applied Sciences (Vol. 9, Issue 1). https://doi.org/10.3844/ajeassp.2016. 107.118.

Baron, S., Estill, C., Steege, A., \& Lalich, N. (2001). Simple solutions: Ergonomics for farm workers. Report Number: DHHS/PUB/NIOSH-2001-111. 58, 146.

Boschman, J. S., Frings-Dresen, M. H. W., \& van der Molen, H. F. (2015). Use of Ergonomic Measures Related to Musculoskeletal Complaints among Construction Workers: A 2-year Follow-up Study. Safety and Health at Work, 6(2), 90-96. https://doi.org/10.1016/j.shaw.2014.1 2.003.

Chander, D. S., \& Cavatorta, M. P. (2017). An observational method for Postural 
Ergonomic Risk Assessment (PERA). International Journal of Industrial Ergonomics, 57, 32-41. https://doi.org/10.1016/j.ergon.2016.1 1.007 .

Charles, L. E., Ma, C. C., Burchfiel, C. M., \& Dong, R. G. (2017). Vibration and ergonomic exposures associated with musculoskeletal disorders of the shoulder and neck. Safety and Health at

Work.

https://doi.org/10.1016/j.shaw.2017.1 0.003 .

Godsiff, D. T., Woods, V., Li, G., \& Buckle, P. (2008). The Development of the Quick Exposure Check (QEC) for Assessing Exposure to Risk Factors for Work-Related usculoskeletal Disorders. Application Ergonomic, 39(1), 57-69. https://doi.org/10.1016/j.apergi.2007. 03.002 .

Halim, I., Omar, A. R., Saman, A. M., \& Othman, I. (2012). Assessment of muscle fatigue associated with prolonged standing in the workplace. Safety and Health at Work, 3(1), 3142.

https://doi.org/10.5491/SHAW.2012. 3.1.31.

Hashim, A. M., Dawal, S. Z. M., \& Yusoff, N. (2012). Ergonomic evaluation of postural stress in school workshop. Work, 41(SUPPL.1), 827-831. https://doi.org/10.3233/WOR-20120249-827.

Hellig, T., Mertens, A., \& Brandl, C. (2018). The interaction effect of working postures on muscle activity and subjective discomfort during static working postures and its correlation with OWAS. International Journal of Industrial Ergonomics, 68(June), 2533.

https://doi.org/10.1016/j.ergon.2018.0
6.006.

Hignett, S., \& McAtamney, L. (2000). Rapid Entire Body Assessment (REBA). Applied Ergonomics, 31(2), 201-205. https://doi.org/10.1016/S00036870(99)00039-3.

Karhu, O., Kansi, P., \& Kuorinka, I. (1977). Correcting working postures in industry: A practical method for analysis. Applied Ergonomics, 8(4), 199-201.

https://doi.org/10.1016/00036870(77)90164-8.

Li, G., \& Buckle, P. (1998). Practical method for the assessment of workrelated musculoskeletal risks - Quick Exposure Check (QEC). Proceedings of the Human Factors and Ergonomics Society, 2(November), 1351-1355.

https://doi.org/10.1177/15419312980 4201905.

McAtamney, L., \& Corlett, E. N. (1993). RULA: a survey method for the investigation of work-related upper limb disorders. Applied Ergonomics, 24(2), 91-99. https://doi.org/10.1016/00036870(93)90080-s.

Mulyati, G. T., Maksum, M., Purwantana, B., \& Ainuri, M. (2019). Ergonomic risk identification for rice harvesting worker. IOP Conference Series: Earth and Environmental Science, 355(1). https://doi.org/10.1088/17551315/355/1/012032.

Mulyati, G. T., Maksum, M., Purwantana, B., \& Ainuri, M. (2020). The workload of rice harvester in Java Indonesia. IOP Conference Series: Earth and Environmental Science, 425(1). https://doi.org/10.1088/17551315/425/1/012035. 
Sa'diyah, N., Maksum, M., \& Mulyati, G. (2019). Reducing MSDs and Physical Workload of Manual Harvesting Peasant. Proceeding of International Conference of Science and Technology, Yogyakarta.

Stanton, N., Hedge, A., Brookhuis, K., Salas, E., \& Hendrick, H. (2005). Handbook of Human Factors and Ergonomics Methods. CRC Press.

Sulistiaji, K. (2007). Buku Alat dan Mesin (alsin) Panen dan Perontokan Padi di Indonesia, Balai Besar Pengembangan Mekanisasi Pertanian, Badan Penelitian dan Pengembangan Pertanian, Serpong.

Sulnawati, E., Abdullah, S., \& Priyati, A. (2016). Analisis Teknis dan Kajian Ergonomika berdasarkan Antropometri pada Penggunaan Traktor Tangan untuk Lahan Sawah. Jurnal Ilmiah Rekayasa Pertanian dan Biosistem, 4(2),239-247.
Swangnetr, M., Kaber, D. B., Puntumetakul, R., \& Gross, M. T. (2014). Ergonomics-related risk identification and pain analysis for farmers involved in rice field preparation. Work (Reading, Mass.), 49(1), 63-71. https://doi.org/10.3233/WOR-131768

Vaidya, R. D., Sontakke, G., \& Ansari, N. A. (2014). Ergonomics Evaluation of Body Posture of Worker In. 1(6), 430434.

van Dieën, J. H. (2010). Evaluation of Work-Rest Schedules with Respect to the Effects of Postural Workload in Standing Work. Ergonomics, 41(12), 1832-1844.

Waters, T.R. and R.B. Dick, 2015, Evidence of Health Risks Associated with Prolonged Standing at Work and Intervention Effectiveness, Rehabil Nurs., 40(3):148-165. doi:10.1002/ rnj.166. 